\title{
Permeability evaluation of Industry 4.0 technologies in cloud-based energy management systems environments - Energy Cloud
}

\author{
Jones Luís Schaefera* (D), Patrícia Stefan de Carvalho ${ }^{\mathrm{a}}$ (D), Augusto Ruhoff ${ }^{\mathrm{b}}$, \\ Johanna Dreher Thomas ${ }^{\mathrm{b}}$, Julio Cezar Mairesse Siluk ${ }^{\mathrm{a}}$ \\ aUniversidade Federal de Santa Maria, Santa Maria, RS, Brasil \\ bUniversidade de Santa Cruz do Sul, Santa Cruz do Sul, RS, Brasil \\ *engjlschaefer@yahoo.com.br
}

\begin{abstract}
:
Paper aims: This article aims to diagnose the penetration level of Industry 4.0 technologies in cloud-based energy management systems, the Energy Cloud.

Originality: The energy sector is undergoing a technological evolution driven by the integration of lndustry 4.0 technologies with energy management systems, making relevant the study of the permeability of these technologies with energy companies.
\end{abstract}

Research method: The research used two articles on Energy Cloud as a theoretical basis and a data collection carried out with managers of renewable energy companies, with the data being analyzed using the MONNA software.

Main findings: The results show that there is a greater understanding and use of the lnternet of Things and Sensors technologies to the detriment of Cloud Computing and Big Data.

Implications for theory and practice: The article shows that there is a need for managers to seek greater familiarization, especially with Cloud Computing and Big Data.

Keywords

Energy management. Energy Cloud. Industry 4.0. MONNA.

How to cite this article: Schaefer, J. L., Carvalho, P. S., Ruhoff, A., Thomas, J. D., \& Siluk, J. C. M. (2021). Permeability evaluation of Industry 4.0 technologies in cloud-based energy management systems environments - Energy Cloud. Production, 31, e20210038. https://doi.org/10.1590/0103-6513.20210038

Received: Apr. 30, 2021; Accepted: July 13, 2021.

\section{Introduction}

The energy sector is in a transition process (Rafindadi \& Mika'llu, 2019), and minimizing energy consumption has become a constant concern for both residential and business consumers (Hakimi \& Hasankhani, 2020). In this sense, energy management models seek to adapt energy consumption to energy demand (Natarajan \& Ashok Kumar, 2017). This statement shows the importance of efficient and effective energy management, both for consumption and generation, transmission, distribution, and storage.

New computational systems and technologies need to be integrated to monitor and control energy data and information so that new policies can be implemented for energy management (Liu et al., 2019). Considering Cloud Computing (CC) environments, data is collected by loT devices and transmitted to cloud storage, being treated and analyzed in centralized databases (Chen et al., 2019). In these CC environments, users' energy data can be stored and accessed easily from a host of application and service platforms (Sivapragash et al., 2019). This way, there is a technological trend that directs the management of energy systems so that it is carried out with the help of new computational technologies such as loT, Sensors, CC, and Big Data. 
These CC structures play an important role in the structure of smart grids, being a technology for storing and monitoring data (Kulkarni et al., 2019). In addition, it provides unlimited storage access, has the potential to run resource-intensive applications, facilitates software access to large amounts of data for remote access (Yassine et al., 2019). Sensors are another powerful technology for monitoring purposes, where a mobile user can choose which sensors to operate based on their requirements (Abed et al., 2019). In this sense, integrating these computer technologies with energy is a challenge that is becoming necessary.

One of these new energy management systems is the Energy Cloud (EC). EC integrates electrical and information infrastructures (Govindarajan et al., 2019) and can be defined as a platform designed with economic and technical conditions to integrate distributed energy systems with smart technologies like smart meters, energy storage systems, microgrids, data systems, and loT technologies (Giordano et al., 2019). Therefore, EC allows the dynamic integration of different technologies in a smart grid environment (Lawrence \& Vrins, 2018), and this evolution of energy systems to EC can happen through the evolution of regulatory aspects to leverage distributed generation and also by lowering the costs of distributed generation and energy storage technologies (Giordano et al., 2019). With that, the evolution to EC environments can happen in small communities, companies, or entire cities, evolving to encompass increasingly larger geographic areas.

EC is an incipient concept and there are no EC environments in operation in Brazil at the time of this research. Some researches guide the future of energy management to CC environments, with total flexibility and versatility for users. For this, the use of distributed renewable energy generation is beneficial in reducing energy consumption, especially if it is linked to energy storage systems and electric vehicles. (Singh et al., 2021), which together form the three basic vectors for the development of the EC. These vectors, even if individually, exert an influence on the users of these systems so that their energy management takes place in a CC environment, using Industry 4.0 technologies such as the Internet of Things (loT), Sensors, CC, and Big Data.

Based on this, the objective of this article is to diagnose the penetration level of Industry 4.0 technologies in energy management systems based on CC environments, the EC. For this, a survey was carried out with managers of companies in the sector of distributed renewable energy generation to verify the level of knowledge and use of technologies in Industry 4.0 that can assist in the processes related to energy management.

The rest of the article is structured as follows, in Section 2 a theoretical framework is shown, in Section 3 the research methodology is presented, in Section 4 the results are presented and discussed, and in Section 5 the conclusion of the research is shown.

\section{Theoretical framework}

In the theoretical framework, the main themes of this article are addressed, starting with energy management, then conceptualizing the EC, and finally, contextualizing the connection of Industry 4.0 technologies with this research.

\subsection{Energy management}

The rise of energy demand is making organizations work to keep demand at acceptable and safe levels (Sequeira et al., 2014). The energy production process still comes from conventional sources and this raises serious climatic concerns (Ahmad et al., 2020). The increase in the use of energy from fossil fuels together with global warming has led to the development of new technologies based on renewable and natural sources (Carvalho et al., 2021). This way, energy management is important in micro-networks, homes, buildings, communities, among others, (Al Faruque \& Vatanparvar, 2016) so that the operation and control of the energy systems are carried out reliably and efficiently (Guo \& Zhao, 2018).

Performing energy management means monitoring and characterizing electricity usage patterns to design user-centered, real-time energy optimization plans (Howell et al., 2019). In traditional energy management systems, it is difficult to control demand and accurately measure users' energy consumption (Wang et al., 2018), which shows the need to use emerging technologies to assist in these tasks. Thus, in energy management systems based on real-time information systems, a large number of sensors and actuators interconnected through a communication network provide the necessary information (Maatoug et al., 2019) for and efficient management.

The growth of information technologies has led the energy sector to adopt innovative measures to do business (Radenković et al., 2020), and with the aid of computational processing techniques, it is possible to obtain insights to achieve the management of this information through the discovery of patterns (de Moraes et al., 2019). Therefore, an energy management system is essential to control energy production and consumption, 
and energy efficiency and cost savings in smart homes and buildings depend heavily on the installed monitoring and control methods (Maatoug et al., 2019).

\subsection{Energy cloud}

The evolution of energy management to $\mathrm{CC}$ environments has given rise to a new concept, the EC. EC connects users so that they can manage their energy through digital platforms using public, private, or hybrid cloud models (Carvalho et al., 2021). Figure 1 presents the functioning scheme of the EC.

Schaefer et al. (2020b) proposed a basic layout for managing the EC, consisting of seven main layers (Physical, Fog, Network, Cloud, Service, Session, and Application) and four management support blocks (Broker, Security and Privacy, Third-Party Services, and Cloud Auditor). In a later proposal, Carvalho et al. (2021) the Regulation layer was added to this layout, where all activities within the scope of regulation and the establishment of legislation are carried out. Figure 2 shows this layout.

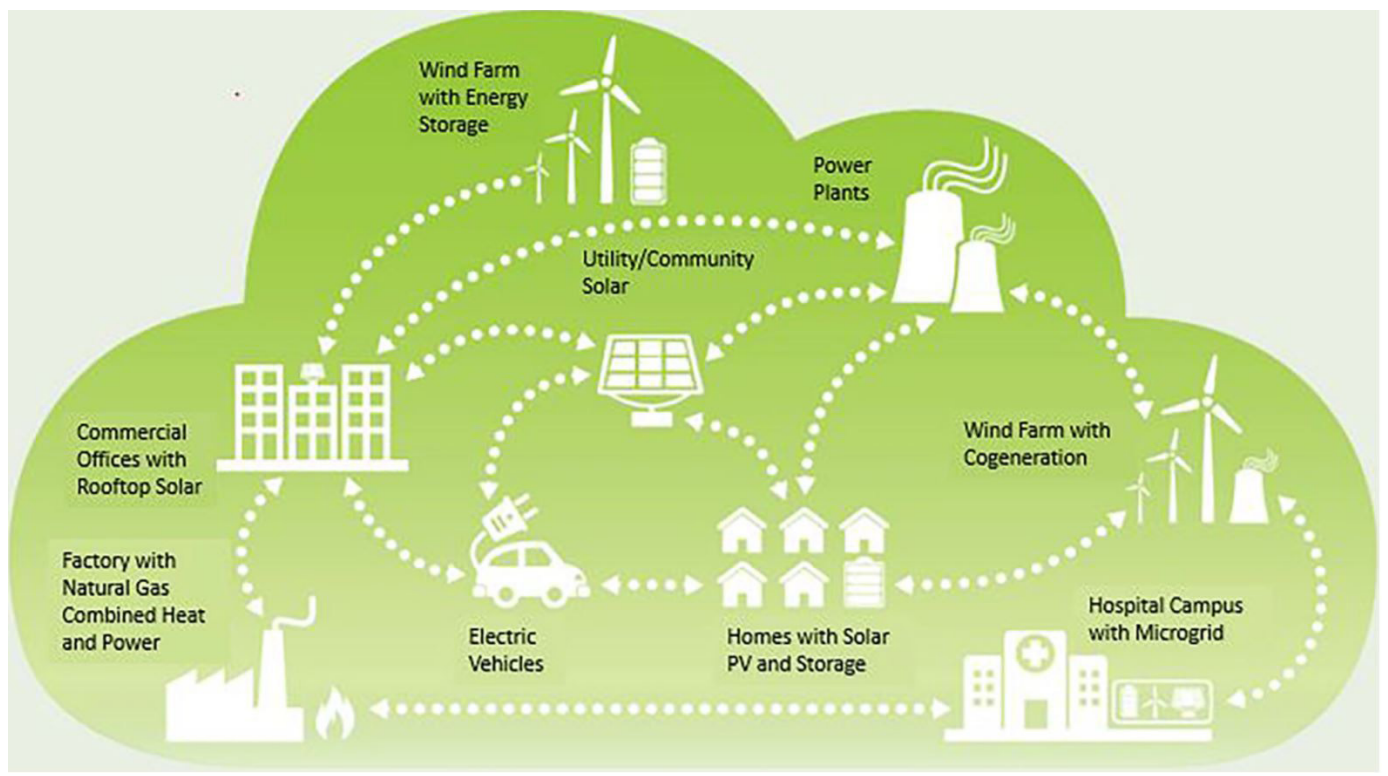

Figure 1. Energy Cloud functioning. Source: Adapted from (Lawrence \& Vrins, 2018).

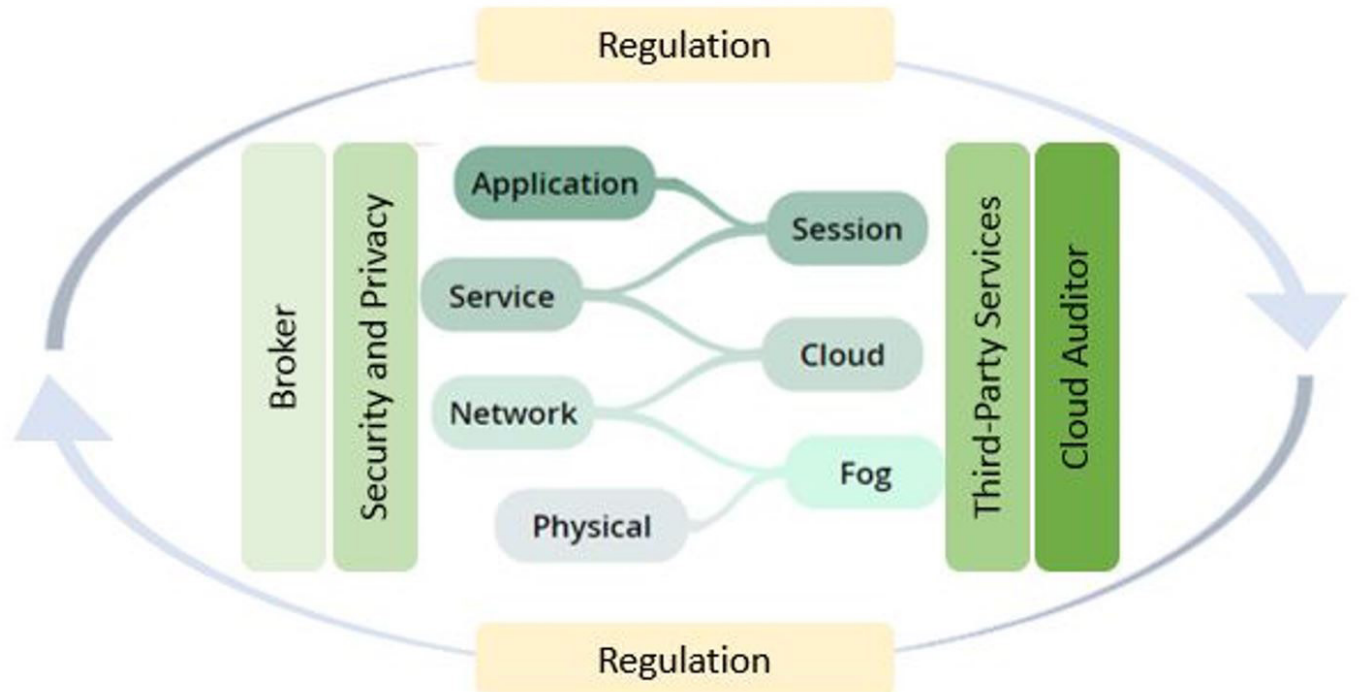

Figure 2. Energy Cloud basic layout. Source: (Carvalho et al., 2021). 
Many factors have contributed to the evolution of the EC, such as the new regulations on electricity generation that are driving the shift to the massive use of distributed energy resources, and the cost of these technologies, which are rapidly decreasing (Giordano et al., 2019). In this sense, this transition from the traditional network to an EC environment would be capable of providing great energy-saving potential, where governments will be able to carry out scientific analyzes of the energy-saving potential and predict the energy use profile (Carvalho et al., 2021).

\subsection{Industry 4.0 technologies}

The EC scenario uses as a technological base some Industry 4.0 tools such as loT, Sensors, CC, and Big Data. loT is a network characterized by physical devices capable of connecting to the internet (da Costa et al., 2019) allowing a rapid generation of data, contributing to the flow of information and the management of organizations (Ahuett-Garza \& Kurfess, 2018). loT is made up of embedded electronic systems, such as internet connection systems and sensors (Kang et al., 2016).

Thus, Sensors technology appears often linked to loT, being responsible for the capture and gross production of data in an integrated way with energy devices. loT combined with CC technology gathers and organizes data through sensors and transmits it to the application platform, where data sharing and exchange takes place (Yang $\&$ Ming, 2021). This sensor data can be sent to any mobile device anywhere, as long as the device is connected to the Internet (Abed et al., 2019).

CC is characterized as a networked infrastructure that supports interconnection with servers for data storage (Wang et al., 2016) running through a data management model that allows ubiquitous and on-demand access to the network through one to several configurable computing resources (Mell \& Grance, 2011). Thus, CC is used in smart grids to perform the tasks of managing large volumes of data and information (Ma et al., 2018). With Big Data it is possible to process these large volumes of data, discovering patterns in the data, and gaining relevant insights to perform energy management (de Moraes et al., 2019), assisting in effective and efficient decision making (Zhou et al., 2016).

\section{Methodological procedures}

To verify which 4.0 technologies are prominently used and which help in the evolutionary process of energy management systems for cloud environments, researches that address the topic of EC with a managerial focus were searched in the literature. A literature review in the Scopus and Web of Science databases with the search terms "energy cloud" and "management" was carried out, with 26 articles and congress articles being found in the Scopus database and 20 in the Web of Science. After reading these researches, it was seen that only the articles of Schaefer et al. (2020b) and Carvalho et al. (2021) address the EC theme with a managerial focus.

Therefore, this research uses this as a base these articles, which mentions that the lnternet of Things (loT), Sensors, CC, and Big Data technologies are responsible for leveraging the evolution of energy management systems, going from centralized and decentralized forms of management, moving to energy management in CC environments (Carvalho et al., 2021; Schaefer et al., 2020b). Based on the layout presented in Section 2.2, the Sensors and loT technologies are implemented in the Physical and Fog layers, while the CC and Big Data technologies are implemented in the Cloud and Service layers (Schaefer et al., 2020b).

Thus, 4.0 loT, Sensors, CC, and Big Data technologies become the variables to be evaluated in this research to verify their permeability in the companies that operate in this type of business, which is the EC. And, to assess this permeability, a research instrument was designed to verify the levels of knowledge and use of these technologies by these companies.

\subsection{Data collect}

As there are no EC environments properly installed, one of the three driving vectors for EC was chosen to carry out data collection. Therefore, data collection was carried out with managers of companies that operate in the area of distributed renewable energy generation.

With the data collection, it was researched with the managers of the companies that work in the distributed generation of renewable energies, the levels of knowledge, and use of these four Industry 4.0 technologies. Data collection was carried out through a survey, and the research instrument used was elaborated with a consent 
form for participation, four questions about knowledge of technologies, one for each technology, and four about the use, also one for each researched technology. Thus, the instrument consisted of 9 questions.

This survey used a 5-point Likert Scale (Tsuchiya \& Hiramoto, 2018), where managers indicated the levels of knowledge and use of Industry 4.0 technologies concerning management activities within the scope of distributed renewable energy generation. Table 1 shows the questions and the score attributed to the managers' responses. The survey instrument was sent to 30 managers of companies operating in the field of distributed renewable energy generation in the Rio Grande do Sul, Brazil, and of these, 21 managers responded to the survey. The survey was conducted in September 2020.

\subsection{Data analysis}

With the survey carried out, it was possible to obtain the relative importance of the variables from the perception of managers (Schaefer et al., 2020a) within the context of EC. Thus, the analysis of the collected data should transform these variables' relativization, in this case, the 4 Industry 4.0 technologies, into information that makes it possible to visualize and discuss the level of permeability of these technologies in the context of EC.

In this sense, the MONNA software (MOORA for Neural Network Analysis) was used, once it makes it possible to classify variables, facilitating decision processes involving multiple criteria (Baierle et al., 2020). Therefore, MONNA software made it possible to classify the technologies of Industry 4.0 both in terms of knowledge and use by managers, in addition to indicating an average rate in each of the situations.

MONNA software uses the MOORA multicriteria method as a base (Brauers, 2002; Brauers \& Zavadskas, 2006) which begins with a decision matrix (1) showing the performance of different alternatives concerning various criteria.

$$
X=\left[\begin{array}{cccccc}
X_{11} & X_{12} & \ldots & \ldots & \ldots & X_{1 n} \\
X_{21} & X_{22} & \ldots & \ldots & \ldots & X_{2 n} \\
\ldots & \ldots & \ldots & \ldots & \ldots & \ldots \\
\ldots & \ldots & \ldots & \ldots & \ldots & \ldots \\
X_{m 1} & X_{m 2} & \ldots & \ldots & \ldots & X_{m n}
\end{array}\right]
$$

Where $X_{i j}$ is the performance measure of technology $i$ for each manager $j, m$ is the number of technologies and $n$ is the number of respondent managers. Then, a relationship system is developed in which each response related to the technologies is compared to a denominator that is a representative of all responses related to those technologies (Equation 2) (Brauers et al., 2010). This denominator is given by the square root of the sum of the squares of each answer concerning technologies, barriers, or actors. This relationship can be expressed by Equation 3.

$$
X_{i j}^{a}=\frac{X_{i j}}{\sqrt{\sum_{i=1}^{m} X_{i j}^{2}(j=1,2, \ldots, n)}}
$$

Table 1. Likert scale used in the survey.

\begin{tabular}{lll}
\hline \multicolumn{1}{c}{ Question } & \multicolumn{1}{c}{ Answer } & Assigned score \\
\hline & 1 do not know about & 1 \\
What is your degree of knowledge concerning & 1 know that there is the technology & 2 \\
the technology? & 1 have some knowledge & 3 \\
& 1 partially dominate & 4 \\
& 1 dominate & 5 \\
What is the degree of use concerning the & 1 do not use & 1 \\
technology? & 1 use very little & 2 \\
& 1 partly use & 3 \\
\hline
\end{tabular}


Where $X_{i j}$ is a dimensionless number that belongs to the range $[0,1]$ that represents the normalized performance of answer $i$ for technologies $j$. For multi-objective optimization, these normalized performances are added in the case of maximization and subtracted in the case of minimization. So, the optimization problem becomes:

$Y_{i}=\sum_{j=1}^{g} X_{i j}^{a}-\sum_{j=g+1}^{n} X_{i j}^{a}$

Where $g$ is the number of responses to be maximized, $(n-g)$ is the number of responses to be minimized, and $Y i$ for evaluating the alternative concerning all attributes. In the case of this research, for the establishment of the average rate of use and/or knowledge of the technologies, all the criteria were considered to be all of the maximizations and with weights equal to 1 .

From the MOORA results, the MONNA software carries out a weighting of the values obtained for each technology within the desired scale, in the case of this research the same values as the survey (between 1 and 5). Thus, two rankings were generated, one for the knowledge of managers concerning technologies and the other for use. Finally, MONNA also calculates an average rate of knowledge and use of 4.0 technologies in energy management systems by the managers of the companies surveyed.

With the rankings and average rates, it is possible to cross these rankings and average rates of knowledge and use of these technologies, thus evaluating the level of penetration of loT, Sensors, CC, and Big Data technologies in energy management systems used by companies that integrate the vector of distributed renewable energy generation.

\section{Results and discussion}

The data obtained were analyzed using the MONNA software. The responses of the 21 managers who responded to the survey were structured in a $21 \mathrm{X} 4$ matrix format, both for the answers related to the managers' knowledge about the 4 technologies studied and for the level of use of these technologies by the managers. Tables 2 and 3 show the classifications obtained for the 4 technologies and also the average rates of knowledge and use.

Both for the level of knowledge and use, the managers indicated the loT and Sensors technologies as the most prominent. About loT, the knowledge and usage rates remained practically stable, at 5 and 4,973 respectively, indicating that there is real knowledge on the part of managers and that this knowledge translates into the use of devices with an aggregated connection to the internet. loT provides well-structured information systems and can deliver better quality results, producing benefits for the organization in different contexts (Baracho et al., 2018). In addition, loT provides a connected and intelligent infrastructure for modern product management, dynamic intelligent manufacturing, and business differentiation, providing integrated product-service solutions to its customers (Delgosha et al., 2021).

Table 2. Results of MONNA software for managers' knowledge about 4.0 technologies.

\begin{tabular}{ccc}
\hline POSITION & TECHNOLOGY & MONNA \\
\hline $1^{\circ}$ & IOT & 5,000 \\
$2^{\circ}$ & SENSORS & 4,236 \\
$3^{\circ}$ & BIG DATA & 3,676 \\
$4^{\circ}$ & CLOUD COMPUTING & 3,439 \\
- & AVERAGE RATE & 4,088 \\
\hline
\end{tabular}

Table 3. Results of MONNA software for the use of 4.0 technologies by managers.

\begin{tabular}{ccc}
\hline POSITION & TECHNOLOGY & MONNA \\
\hline $1^{\circ}$ & SENSORS & 5,000 \\
$2^{\circ}$ & IOT & 4,973 \\
$3^{\circ}$ & CLOUD COMPUTING & 3,843 \\
$4^{\circ}$ & BIG DATA & 3,307 \\
- & AVERAGE RATE & 4,281 \\
\hline
\end{tabular}


Concerning Sensors technology, despite having a rate of 4,236 about the knowledge of managers, the utilization rate goes to 4,973. This indicates that despite using and carrying out the commercialization and installation of devices related to Sensors technology, many managers are not fully aware of how those devices work. In this sense, the use of loT platforms that integrate various types of sources (such as sensors) provides valuable information to help improve efficiency, drive cost savings and achieve optimization. (Illa \& Padhi, 2018). The use of sensors is an important method of data collection, and the greater the intelligence of the system, the greater the demand for sensors (Ji, 2021). Therefore, considering that we are moving towards a more intelligent future, having an understanding of the functioning of this equipment is essential for the good performance of organizations.

Big Data technology is the third at the level of knowledge, with a rate of 3,676, and the fourth at the level of use, with a rate of 3,307. CC technology is the fourth in terms of knowledge, with a rate of 3,439, and the third in terms of use, with a rate of 3,843. These rates end up showing that, although they are contributing to the development of EC environments, there is no real understanding of how CC is contributing and becoming the main reference in this process. Therefore, these results show that there is a need for managers to seek greater knowledge about these technologies before coordinating their use in their businesses.

There is uncertainty on the part of public organizations on how to implement Big Data, this arises from the different opinions, expectations, assumptions, and understandings of public managers about the use of big data in public administrations (Guenduez et al., 2020). For the authors, these different understandings about Big Data represent a major challenge for the definition of organizational and technical standards, making it difficult to reach an agreement on a future roadmap for the use of Big Data in companies, delaying the implementation of Big Data. In this context of using Big Data in organizations, the study by Calic \& Ghasemaghaei (2020) demonstrated its importance for organizational innovation in business practices and external relations, as they significantly and substantially improve economic, ethical-legal, and philanthropic performance.

Finally, the average rates for knowledge and use by managers about this group of technologies were also calculated using the MONNA software. The knowledge average rate was 4,088, while the utilization average rate was 4,281 . These results present an important reality to be circumvented, that of reversing rates. The utilization average rate is higher than that of knowledge related to technologies 4.0, which shows that sometimes managers endorse the use of technologies even without knowing all the advantages and/or disadvantages that technologies can add to their business.

\section{Conclusion}

The purpose of this article was to diagnose the penetration levels of Industry 4.0 technologies for EC environments management. With the survey carried out, it was possible to obtain a perception of the managers of distributed generation of renewable energies companies concerning the knowledge and the use of loT, Sensors, $\mathrm{CC}$, and Big Data technologies in the energy management systems. The managers of companies that operate in the distributed generation of renewable energies were invited to participate because this line of business, together with electric vehicles and energy storage systems, form the basis vectors for the development of the EC. Thus, it can be considered that the research objective was successfully achieved.

The research showed that managers have a good level both for knowledge and for the use of loT and Sensors technologies, while for CC and Big Data technologies they had lower rates for both knowledge and use. This shows that managers still do not have a consolidated awareness regarding the benefits that CC and Big Data can bring to their business. Finally, the average rate of use of 4.0 technologies was greater than the degree of knowledge related to these technologies, corroborating the previous statement and showing that there is a need for a greater understanding of the role of 4.0 technologies in the management of electricity now and in the future.

This research was limited to researching Industry 4.0 technologies that can contribute to the maturation of EC environments. As future work, it can be suggested to research with a wide scope of technologies, developing a roadmap of how they can be added to these new environments of energy management.

\section{References}

Abed, S., Al-Shayeji, M., \& Ebrahim, F. (2019). A secure and energy-efficient platform for the integration of Wireless Sensor Networks and Mobile Cloud Computing. Computer Networks, 165, 106956. http://dx.doi.org/10.1016/j.comnet.2019.106956.

Ahmad, T., Zhang, H., \& Yan, B. (2020). A review on renewable energy and electricity requirement forecasting models for smart grid and buildings. Sustainable Cities and Society, 55, 102052. https://doi.org/10.1016/j.scs.2020.102052. 
Ahuett-Garza, H., \& Kurfess, T. (2018). A brief discussion on the trends of habilitating technologies for Industry 4.0 and Smart manufacturing. Manufacturing Letters, 15, 60-63. http://dx.doi.org/10.1016/j.mfglet.2018.02.011.

Al Faruque, M. A., \& Vatanparvar, K. (2016). Energy Management-as-a-Service over Fog Computing Platform. IEEE Internet of Things Journal, 3(2), 161-169. http://dx.doi.org/10.1109/J10T.2015.2471260.

Baierle, I. C., Schaefer, J. L., Sellitto, M. A., Fava, L. P., Furtado, J. C., \& Nara, E. O. B. (2020). MOONA software for survey classification and evaluation of criteria to support decision-making for properties portfolio. International Journal of Strategic Property Management, 24(4), 226-236. http://dx.doi.org/10.3846/ijspm.2020.12338.

Baracho, R., Cunha, l., \& Pereira Junior, M. L. (2018). Information modeling and information retrieval for the lnternet of things (loT) in Buildings. Journal of Systemics, Cybernetics and Informatics, 16(2), 85-91.

Brauers, W. K. (2002). The multiplicative representation for multiple objectives optimization with an application for arms procurement. Naval Research Logistics, 49(4), 327-340. http://dx.doi.org/10.1002/nav.10014.

Brauers, W. K. M., Ginevičius, R., \& Podvezko, V. (2010). Lietuvos regioninės plètros daugiaaspektis vertinimas moora metodu. Technological and Economic Development of Economy, 16(4), 613-640. http://dx.doi.org/10.3846/tede.2010.38.

Brauers, W. K., \& Zavadskas, E. K. (2006). The MOORA method and its application to privatization in a transition economy. Control and Cybernetics, 35, 445-469.

Calic, G., \& Ghasemaghaei, M. (2020). Big data for social benefits: Innovation as a mediator of the relationship between big data and corporate social performance. Journal of Business Research, 131, 391-401. http://dx.doi.org/10.1016/j.jbusres.2020.11.003.

Carvalho, P. S., Siluk, J. C. M., Schaefer, J. L., Pinheiro, J. R., \& Schneider, P. S. (2021). Proposal for a new layer for energy cloud management: the regulatory layer. International Journal of Energy Research, 45(7), 9780-9799. https://doi.org/10.1002/er.6507.

Chen, Y.-Y., Lin, Y.-H., Kung, C.-C., Chung, M.-H., \& Yen, 1.-H. (2019). Design and implementation of cloud analytics-assisted smart power meters considering advanced artificial intelligence as edge analytics in demand-side management for smart homes. Sensors (Basel, Switzerland), 19(9), 2047. http://dx.doi.org/10.3390/s19092047. PMid:31052502.

da Costa, M. B., dos Santos, L. M. A. L., Schaefer, J. L., Baierle, I. C., \& Nara, E. O. B. (2019). Industry 4.0 technologies basic network identification. Scientometrics, 121(2), 977-994. http://dx.doi.org/10.1007/s11192-019-03216-7.

de Moraes, J., Schaefer, J. L., Schreiber, J. N. C., Thomas, J. D., \& Nara, E. O. B. (2019). Algorithm applied: attracting MSEs to business associations. Journal of Business and Industrial Marketing. http://dx.doi.org/10.1108/JBIM-09-2018-0269.

Delgosha, M. S., Hajiheydari, N., \& Talafidaryani, M. (2021). Discovering loT implications in business and management: a computational thematic analysis. Technovation, 102236. In press. http://dx.doi.org/10.1016/j.technovation.2021.102236.

Giordano, A., Mastroianni, C., Menniti, D., Pinnarelli, A., \& Sorrentino, N. (2019). An energy community implementation: the unical energy cloud. Electronics (Switzerland), 8(12), 1517. http://dx.doi.org/10.3390/electronics8121517.

Govindarajan, R., Meikandasivam, S., \& Vijayakumar, D. (2019). Cloud computing based smart energy monitoring system. International Journal of Scientific and Technology Research, 8(10), 886-890.

Guenduez, A. A., Mettler, T., \& Schedler, K. (2020). Technological frames in public administration: what do public managers think of big data? Government Information Quarterly, 37(1), 101406. http://dx.doi.org/10.1016/j.giq.2019.101406.

Guo, Y., \& Zhao, C. (2018). Islanding-aware robust energy management for microgrids. IEEE Transactions on Smart Grid, 9(2), 13011309. http://dx.doi.org/10.1109/TSG.2016.2585092.

Hakimi, S. M., \& Hasankhani, A. (2020). Intelligent energy management in off-grid smart buildings with energy interaction. Journal of Cleaner Production, 244, 118906. http://dx.doi.org/10.1016/j.jclepro.2019.118906.

Howell, S. K., Wicaksono, H., Yuce, B., McGlinn, K., \& Rezgui, Y. (2019). User centered neuro-fuzzy energy management through semantic-based optimization. IEEE Transactions on Cybernetics, 49(9), 3278-3292. http://dx.doi.org/10.1109/TCYB.2018.2839700. PMid:30028719.

1lla, P. K., \& Padhi, N. (2018). Practical guide to smart factory transition using loT, big data and edge analytics. IEEE Access : Practical Innovations, Open Solutions, 6, 55162-55170. http://dx.doi.org/10.1109/ACCESS.2018.2872799.

Ji, Y. (2021). Application of fault detection using distributed sensors in smart cities. Physical Communication, 46, 101182. http://dx.doi. org/10.1016/j.phycom.2020.101182.

Kang, H. S., Lee, J. Y., Choi, S., Kim, H., Park, J. H., Son, J. Y., Kim, B. H., \& Noh, S. D. (2016). Smart manufacturing: past research, present findings, and future directions. International Journal of Precision Engineering and Manufacturing - Green Technology, 3(1), 111-128. https://doi.org/10.1007/s40684-016-0015-5.

Kulkarni, N., Lalitha, S. V. N. L., \& Deokar, S. A. (2019). Real time control and monitoring of grid power systems using cloud computing. Iranian Journal of Electrical and Computer Engineering, 9(2), 941-949. http://dx.doi.org/10.11591/ijece.v9i2.pp941-949.

Lawrence, M., \& Vrins, J. (2018). Energy Cloud 4.0 - Capturing Business Value through Disruptive Energy Platforms (pp. 1-46). USA: Guidehouse Consulting.

Liu, Y., Yang, C., Jiang, L., Xie, S., \& Zhang, Y. (2019). Intelligent edge computing for iot-based energy management in smart cities. IEEE Network, 33(2), 111-117. http://dx.doi.org/10.1109/MNET.2019.1800254.

Ma, Y., Zhao, F., Zhou, X., \& Gao, Z. (2018). Summary of cloud computing technology in smart grid. Proceedings of 2018 IEEE International Conference on Mechatronics and Automation, ICMA 2018 (pp. 253-258). USA: IEEE. http://dx.doi.org/10.1109/ICMA.2018.8484418

Maatoug, A., Belalem, G., \& Mahmoudi, S. (2019). Fog computing framework for location-based energy management in smart buildings. Multiagent and Grid Systems, 15(1), 39-56. http://dx.doi.org/10.3233/MGS-190301.

Mell, P., \& Grance, T. (2011). The NIST Definition of Cloud Computing Recommendations of the National Institute of Standards and Technology. Retrieved in 2021, April 30, from http://faculty.winthrop.edu/domanm/csci411/Handouts/NIST.pdf

Natarajan, G., \& Ashok Kumar, L. (2017). Implementation of loT based smart village for the rural development. International Journal of Mechanical Engineering and Technology, 8(8), 1212-1222. 
Radenković, M., Bogdanović, Z., Despotović-Zrakić, M., Labus, A., \& Lazarević, S. (2020). Assessing consumer readiness for participation in loT-based demand response business models. Technological Forecasting and Social Change, 150, 119715. http://dx.doi.org/10.1016/j. techfore.2019.119715.

Rafindadi, A. A., \& Mika'llu, A. S. (2019). Sustainable energy consumption and capital formation: Empirical evidence from the developed financial market of the United Kingdom. Sustainable Energy Technologies and Assessments, 35, 265-277. http://dx.doi.org/10.1016/j. seta.2019.07.007.

Schaefer, J. L., Baierle, 1. C., Sellitto, M. A., Siluk, J. C. M., Furtado, J. C., \& Nara, E. O. B. (2020a). Competitiveness scale as a basis for Brazilian Small and Medium-Sized Enterprises. Engineering Management Journal, 1-17. http://dx.doi.org/10.1080/10429247.20 20.1800385

Schaefer, J. L., Siluk, J. C. M., Carvalho, P. S., Renes Pinheiro, J., \& Schneider, P. S. (2020b). Management Challenges and opportunities for energy cloud development and diffusion. Energies, 13(16), 4048. http://dx.doi.org/10.3390/en 13164048.

Sequeira, H., Carreira, P., Goldschmidt, T., \& Vorst, P. (2014). Energy cloud: Real-time cloud-native energy management system to monitor and analyze energy consumption in multiple industrial sites. In Proceedings - 2014 IEEE/ACM 7th International Conference on Utility and Cloud Computing, UCC 2014 (pp. 529-534). USA: IEEE. http://dx.doi.org/10.1109/UCC.2014.79.

Singh, P., Dhundhara, S., Verma, Y. P., \& Tayal, N. (2021). Optimal battery utilization for energy management and load scheduling in smart residence under demand response scheme. Sustainable Energy, Grids and Networks, 26, 100432. http://dx.doi.org/10.1016/j. segan.2021.100432.

Sivapragash, C., Padmanaban, S., Eklas, H., Holm-Nielsen, J. B., \& Hemalatha, R. (2019). Location-based optimized service selection for data management with cloud computing in smart grids. Energies, 12(23). http://dx.doi.org/10.3390/en12234517.

Tsuchiya, Y., \& Hiramoto, N. (2018). Measuring consensus and dissensus: a generalized index of disagreement using conditional probability. Information Sciences, 439-440, 50-60. http://dx.doi.org/10.1016/j.ins.2018.02.003.

Wang, S., Wan, J., Li, D., \& Zhang, C. (2016). Implementing smart factory of Industrie 4.0: an outlook. International Journal of Distributed Sensor Networks, 12(1), 3159805. http://dx.doi.org/10.1155/2016/3159805.

Wang, Y., Huang, Y., Wang, Y., Zeng, M., Li, F., Wang, Y., \& Zhang, Y. (2018). Energy management of smart micro-grid with response loads and distributed generation considering demand response. Journal of Cleaner Production, 197, 1069-1083. http://dx.doi. org/10.1016/j.jclepro.2018.06.271.

Yang, C., \& Ming, H. (2021). Detection of sports energy consumption based on loTs and cloud computing. Sustainable Energy Technologies and Assessments, 46, 101224. http://dx.doi.org/10.1016/j.seta.2021.101224.

Yassine, A., Singh, S., Hossain, M. S., \& Muhammad, G. (2019). loT big data analytics for smart homes with fog and cloud computing. Future Generation Computer Systems, 91, 563-573. http://dx.doi.org/10.1016/j.future.2018.08.040.

Zhou, K., Fu, C., \& Yang, S. (2016). Big data driven smart energy management: from big data to big insights. Renewable \& Sustainable Energy Reviews, 56, 215-225. http://dx.doi.org/10.1016/j.rser.2015.11.050. 